\title{
ENRAIZAMENTO DE PLÂNTULAS DE MIRTILEIRO EM CONDIÇÃO EX VITRO COM DIFERENTES SUBSTRATOS ${ }^{1}$
}

\author{
TÂNIA REGINA PELIZZA², DANIELE CAMARGO NASCIMENTO ${ }^{3}$, LUANA BORGES AFFONSO $^{4}$, \\ SAMILA SILVA CAMARGO ${ }^{5}$, BRUNO CARRA ${ }^{5}$, MÁRCIA WULFF SCHUCH $^{6}$
}

RESUMO - O objetivo deste trabalho foi avaliar a capacidade de enraizamento ex vitro de plântulas de mirtileiro cultivares Bluebelle, Woodard e Georgiagem em diferentes substratos. O experimento foi instalado no período de fevereiro a abril $/ 2009$, em casa de vegetação, com temperatura de $\pm 25^{\circ} \mathrm{C}$, na Universidade Federal de Pelotas (UFPel/FAEM), em Pelotas (RS). As plântulas (sete gemas e sete folhas + ápice caulinar), após imersas em AIB (250 mg. $\left.\mathrm{L}^{-1}\right)$ por 10 minutos, foram acondicionadas em bandejas plásticas fechadas, com

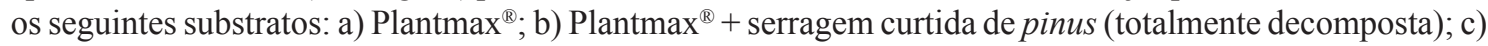
serragem curtida; d) Plantmax ${ }^{\circledR}+$ vermiculita expandida de granulometria média, e e) vermiculita expandida de granulometria média. O delineamento experimental foi o inteiramente casualizado, com arranjo fatorial $3 \times 5$, sendo três cultivares e cinco substratos, com quatro repetições por tratamento, sendo cada repetição constituída de 8 explantes. Após 75 dias, avaliaram-se a percentagem de enraizamento das plântulas, a formação de calo, as plântulas sobreviventes, o comprimento e o número de raízes, o comprimento da maior raiz, a altura das plântulas, o número de brotações e a biomassa fresca total. Pode-se concluir que os melhores substratos para enraizamento ex vitro de plântulas de mirtileiro são vermiculita expandida de granulometria média, serragem curtida de pinus e Plantmax ${ }^{\circledR}+$ vermiculita expandida de granulometria média. Maior potencial de enraizamento ex vitro é alcançado com as cultivares Bluebelle e Woodard.

Termos para indexação: Cultura de tecidos, micropropagação, Plantmax $^{\circledR}$, serragem, Vaccinium sp, vermiculita.

\section{ROOTING OF BLUEBERRY SEEDLINGS UNDER EX VITRO CONDITIONS AND DIFFERENT SUBSTRATES}

\begin{abstract}
The objective of this study was to measure the capacity of ex vitro rooting of blueberry seedlings cultivars Bluebelle, Woodard and Georgiagem under different substrates. The experiment was carried out from February to April, 2009 in greenhouse at $\pm 25^{\circ} \mathrm{C}$, set at Universidade Federal de Pelotas (UFPel/FAEM) in Pelotas (RS). The seedlings (seven buds and seven leaves + stem apex) were immersed in IBA for 10 minutes, and after were put in closed plastic trails filled up with the following substrates: a) Plantmax ${ }^{\circledR}$, b) Plantmax ${ }^{\circledR}+$ old pine sawdust (totally degraded), c) old pine sawdust, d) Plantmax ${ }^{\circledR}+$ medium grade expanded vermiculite and e) medium grade expanded vermiculite. The experimental design was completely randomized in a $3 \times 5$ factorial arrangement, with three cultivars and five substrates. There were four replications per treatment and eight seedlings per replication. After 75 days the percentage of rooting seedlings, callus formation, surviving seedlings, length and number of roots, length of the largest root, seedlings height, number of shoots and total fresh biomass were assessed. The better substrates to ex vitro rooting of blueberry seedlings are medium grade expanded vermiculite, old pine sawdust and Plantmax $®$ + medium grade expanded vermiculite. Higher potential of ex vitro rooting is achieved with the cultivars Bluebelle and Woodard.
\end{abstract}

Index terms: Tissue culture, micropropagation, Plantmax ${ }^{\circledR}$, sawdust, Vaccinium sp, vermiculite.

\footnotetext{
${ }^{1}$ (Trabalho 122-11). Recebido em: 06-04-2011. Aceito para publicação em: 01-11-2011.

${ }^{2}$ Eng. Agr., Dra., Bolsista PRODOC/CAPES, Centro de Ciências Agroveterinárias (CAV), Universidade do Estado de Santa Catarina (UDESC). Avenida Luiz de Camões 2090, Bairro Conta Dinheiro, 88520000 - Lages-SC. E-mail: trp_mestagro@hotmail.com ${ }^{3}$ Bióloga, Mestre em Fruticultura de Clima Temperado, Universidade Federal de Pelotas (UFPel/FAEM), Pelotas-RS. E-mail: dcn.biologia@gmail.com

${ }^{4}$ Eng. Agr., doutoranda em Sistemas de Produção Agrícola Familiar, Universidade Federal de Pelotas (UFPEL/FAEM), Pelotas-RS.. E-mail: luanaffonso@yahoo.com.br

${ }^{5}$ Estudante de Agronomia, Bolsista de Iniciação Científica, Universidade Federal de Pelotas (UFPel/FAEM). Pelotas- RS. E-mail: brunocarra@hotmail.com; samilasc@yahoo.com.br

${ }^{6}$ Prof. Adjunto, Departamento de Fitotecnia, Universidade Federal de Pelotas (UFPel/FAEM). Pelotas-RS. E-mail: marciaws@ufpel.tche.br
} 


\section{INTRODUÇÃO}

O mirtilo é um dos frutos que compõem os chamados pequenos frutos, juntamente com amorapreta, framboesa e morango, que detêm a maior área cultivada no Brasil (ANTUNES, 2005). Estima-se em cerca de 100 ha a área de cultivo do mirtileiro no Brasil, onde 30 ha se localizam em Vacaria, 20 ha em Caxias do Sul e 10 ha na região de Pelotas, no Rio Grande do Sul. O restante está disperso em pequenos pomares em outros municípios do Rio Grande do Sul, Santa Catarina, São Paulo e Minas Gerais (PAGOT, 2006).

A propagação de plantas é a primeira fase da produção vegetal. A escolha do método de propagação mais adequado depende da espécie e do objetivo a ser alcançado. Um bom método de propagação deve ser de baixo custo, fácil execução e deve proporcionar a obtenção de elevado percentual de mudas. No caso da cultura do mirtileiro, tradicionalmente, a estaquia tem sido a técnica mais utilizada para propagá-lo. No entanto, os resultados práticos são bastante variáveis em função da cultivar utilizada (FACHINELLO et al., 2005).

A micropropagação de plantas é uma técnica que possibilita a obtenção de novas plantas em um curto período de tempo e em pequeno espaço. $\mathrm{O}$ uso da cultura de tecidos na cultura do mirtileiro vem sendo conduzido com sucesso, principalmente no Uruguai, que utiliza uma técnica eficiente, denominada AR-VITRO, para a produção desta espécie e conservação do germoplasma in vitro (CASTILLO et al., 2004). Uma das etapas realizadas na micropropagação é o enraizamento dos explantes que classicamente tem sido realizado in vitro. Porém, como no enraizamento in vitro as raízes formadas apresentam dificuldades de sobrevivência no estágio de aclimatização (McCLELLAND et al.,1990), além do custo de produção ser maior (FERRI et al., 1998). Assim, o uso do enraizamento ex vitro se apresenta como uma alternativa, pois de acordo com Pedrotti e Voltolini (2001) esta técnica possibililita a redução em $50 \%$ dos custos finais de produção de uma nova planta.

Aliada à técnica do enraizamento ex vitro, um substrato com boas características também é importante para proporcionar melhor enraizamento de plântulas, já que este material suporte possibilita melhores condições físicas, químicas e biológicas para o desenvolvimento das plantas (KÄMPF, 2001; BATAGLIA; ABREU, 2001). Segundo Ferraz et al. (2005), a turfa, de origem vegetal, e a vermiculita, de origem mineral, são os substratos mais utilizados mundialmente.
Assim sendo, conduziu-se este experimento com o objetivo de avaliar a resposta ao enraizamento ex vitro de três cultivares de mirtileiro (Georgiagem - Grupo Highbush e Bluebelle e Woodard - Grupo Rabbiteye) com o uso de diferentes substratos.

\section{MATERIAL E MÉTODOS}

O experimento foi realizado em casa de vegetação pertencente ao Departamento de Fitotecnia da Faculdade de Agronomia Eliseu Maciel, da Universidade Federal de Pelotas-RS, no Câmpus Capão do Leão, durante os meses de fevereiro a abril de 2009.

O material inicial, originado de plantas-matrizes de mirtileiro 'Georgiagem' (Vaccinium corymbosum), pertencente ao grupo Highbush e 'Bluebelle', e 'Woodard' (Vaccinium ashei), pertencente ao grupo Rabbiteye, acondicionadas em casa de vegetação, foi estabelecido e multiplicado em laboratório, em meio nutritivo WPM (Wood Plant Media) (LLOYD; McCOWN, 1980), por aproximadamente 10 subcultivos. Foram selecionadas e utilizadas plântulas com sete gemas e sete folhas + ápice caulinar que foram imersas por 10 minutos em solução de AIB (ácido indolbutírico), na concentração de $250 \mathrm{mg} \mathrm{L}^{-1}$. Em seguida, fez-se o estaqueamento em bandejas plásticas transparentes fechadas (cumbucas plásticas), contendo cinco diferentes substratos: a) Plantmax ${ }^{\circledR}$; b) Plantmax ${ }^{\circledR}+$ serragem curtida de pínus; c) serragem curtida de pínus; d) Plantmax ${ }^{\circledR}+$ vermiculita expandida de granulometria média, e e) vermiculita expandida de granulometria média. O AIB foi diluído em $\mathrm{NaOH} 1 \mathrm{~N}$ e em álcool etílico a $70 \%$. Todos os substratos foram autoclavados, por 30 minutos, em temperatura de $120^{\circ} \mathrm{C}$ e $1,5 \mathrm{ATM}$ de pressão. A vermiculita expandida utilizada neste experimento apresentava granulometria média (número 3), e a serragem curtida, adquirida junto à madeireira da região, tinha como origem madeira de pínus, apresentava coloração marrom e foi utilizada após seis meses de decomposição, realizada na própria madeireira pela ação do tempo. Quando associados dois substratos, a proporção utilizada foi de 1:1 (v/v). Após o estaqueamento, as bandejas foram acondicionadas em casa de vegetação com temperatura controlada ( \pm $25{ }^{\circ} \mathrm{C}$ ). A análise dos substratos apresentou valores de $\mathrm{pH}$ contidos na Tabela 1 . A média no número de horas de insolação e a radiação solar média, máxima e mínima observada no Câmpus Capão do Leão, na Universidade Federal de Pelotas, são listadas na Tabela 2.

Aos 75 dias, foram avaliados: percentagem de enraizamento, formação de calo, plântulas sobreviventes, comprimento das raízes, comprimento da 
maior raiz, número de raízes, altura das plântulas, biomassa fresca total e número de brotações.

O delineamento experimental foi o inteiramente casualizado, em fatorial $3 \times 5$, com quatro repetições por tratamento, sendo cada repetição constituída de 8 plântulas. Os dados foram submetidos à análise de variância, e as médias dos tratamentos, comparadas estatisticamente pelo teste de Tukey ( $p<$ $0,05)$, por meio do programa estatístico Winstat 2.0 (MACHADO; CONCEIÇÃO, 2003), sendo os dados expressos em percentagem transformados em arcosseno da raiz quadrada de $\mathrm{x} / 100$, e os dados numéricos foram transformados em raiz quadrada de $\mathrm{x}+0,5$.

\section{RESULTADOS E DISCUSSÃO}

A análise de variância evidenciou interação entre os fatores cultivares $\mathrm{x}$ substrato para as variáveis comprimento e número de raízes, tamanho da maior raiz, altura do explante, massa fresca total e número de brotações. Para as variáveis percentagem de enraizamento e percentagem de sobrevivência dos explantes, houve efeito da cultivar; para percentagem de formação de calo, houve efeito do substrato e da cultivar.

Quanto à percentagem de enraizamento das plântulas, foi verificado que as cultivares Bluebelle e Woodard, ambas pertencentes ao grupo Rabbiteye, apresentaram melhores resultados $(98,7$ e $97,5 \%$ de enraizamento, respectivamente), enquanto a cultivar Georgiagem (Grupo Highbush) apresentou 77,5\% de enraizamento (Figura 1A). Para a variável percentagem de plântulas sobreviventes, foi observado comportamento semelhante, pois 'Bluebelle' e 'Woodard' apresentaram 99,4 e 100\% de sobrevivência, respectivamente, enquanto 'Georgiagem' (91,9\%) apresentou diferença estatística das demais (Figura 1B). Trevisan et al. (2008) verificaram em estacas herbáceas de mirtileiro que as cultivares Bluebelle e Briteblue apresentaram $50 \%$ de enraizamento,enquanto 'Climax' apresentou 19,8\%, o que caracteriza a diferença do potencial genético de cada cultivar em emitir raízes. Damiani e Schuch (2009b) observaram que a porcentagem de enraizamento in vitro de mirtileiro é dependente do substrato, da cultivar e do ambiente de cultivo, podendo esta condição ser a sala de crescimento, em laboratório, onde se tem condições controladas de luz, temperatura e fotoperíodo, ou a casa de vegetação, onde se têm condições limitadas de controle ambiental. Dentre as cultivares avaliadas, Georgiagem mostrou-se superior à Delite em condições de enraizamento em casa de vegetação.

A percentagem de formação de calo nos explantes de mirtileiro pode ser considerada baixa em todas as cultivares. 'Woodard' foi a que apresentou maior valor $(17,1 \%)$. 'Bluebelle' apresentou $12,6 \%$ de explantes com calo, e 'Georgiagem' 6,9\%, não diferindo estatisticamente entre si (Figura 1D). Como a percentagem de enraizamento e de plântulas sobreviventes foi menor para a cultivar Georgiagem, justifica-se a pequena formação de calo nesta cultivar. Também foi possível observar que, quando utilizado o substrato à base de serragem curtida de pínus, não se observa formação de calo nas plântulas de mirtileiro, nas três cultivares avaliadas (Figura 1C), ou seja, esse substrato possibilita a formação direta das raízes. É possível que o baixo valor de pH observado nesse substrato (Tabela 1) possa ter contribuído para tal resultado, já que Vaccinium spp. se adapta melhor a baixos valores de $\mathrm{pH}$. Miranda e Miranda (2000), em trabalho realizado com propagação de estacas semilenhosas de mogno em câmara úmida, observaram menor formação de calos com o uso de serragem (18\%) e de areia fina (28\%).

De modo geral, o comprimento médio das raízes, nas três cultivares utilizadas, foi maior quando se utilizou vermiculita expandida de granulometria média (Tabela 3). A cultivar Bluebelle também apresentou o mesmo resultado quando utilizado Plantmax $^{\circledR}+$ vermiculita expandida de granulometria média. Maciel et al. (2002) obtiveram resultados distintos com o uso de diferentes substratos no enraizamento de porta-enxerto Marubakaido, aos 90 dias de enraizamento. Segundo Damiani e Schuch (2009b), a vermiculita apresenta comportamento similar à perlita e ao ágar+carvão ativado, quando utilizadas no meio de cultura para enraizamento de mirtileiro e ambientados em casa de vegetação, avaliando-se o comprimento da maior raiz.

Quando avaliada cada cultivar, o substrato vermiculita expandida de granulometria média proporcionou melhores resultados quanto ao comprimento da maior raiz (Tabela 3 ). A vermiculita oferece boa aeração, alta capacidade de retenção de água, baixo peso (KÄMPF, 2005) e não dissemina doenças (HOFFMANN et al., 2005), características importantes no processo de enraizamento. Segundo Xavier et al. (2009), é recomendável testar cada substrato de acordo com as condições ambientais e a espécie a ser propagada.

Para a cultivar Georgiagem, foram observadas diferenças entre os substratos utilizados para a variável número médio de raízes (Tabela 3 ). Já 'Woodard' apresentou maior número médio de raízes quando se utilizou serragem curtida de pínus, e 'Bluebelle' utilizando vermiculita expandida de granulometria média, embora este substrato não tenha diferido do uso de serragem curtida de pínus 
e Plantmax ${ }^{\circledR}+$ vermiculita expandida de granulometria média. Além do substrato utilizado, as condições ambientais proporcionadas aos explantes também interferem na resposta ao número de raízes, conforme observado por Maciel et al. (2002), assim como a época do ano em que se realiza o enraizamento, pois de acordo com Damiani e Schuch (2009a), no verão, obtêm-se melhores resultados.

As cultivares Bluebelle e Georgiagem não apresentaram diferenças entre os substratos testados quanto à altura média das plântulas, quando comparadas individualmente (Tabela 4). No entanto, 'Woodard' apresentou maior altura de plântula no substrato serragem curtida de pínus. Parece haver uma relação oposta para estas cultivares quando comparadas com o comprimento de raiz, pois para maior comprimento de raízes há menor altura de plântula.

'Georgiagem' não apresentou diferença estatística entre os substratos para biomassa fresca total (Tabela 4), enquanto para Bluebelle o melhor substrato foi vermiculita expandida de granulometria média e para Woodard, além de vermiculita expandida de granulometria média, também Plantmax ${ }^{\circledR}$ + vermiculita expandida de granulometria média foram eficientes. Porém, dentre todos os substratos, serragem curtida de pínus foi o melhor para todas as cultivares. Damiani e Schuch (2009b) observaram maior matéria fresca de mirtileiro por explante quando enraizado in vitro em sala de crescimento, se comparado aos enraizados em casa de vegetação. No entanto, atribuem também haver influência da massa de calos formadas no peso final dos explantes.

O número médio de brotos para 'Georgiagem' foi maior na serragem curtida de pínus (Tabela 4). Para 'Bluebelle', além desta, também Plantmax ${ }^{\circledR}+$ serragem curtida de pínus foram eficientes, enquanto para 'Woodard' não houve diferença para os substratos. De modo geral, a diferença apresentada entre as cultivares de mirtileiro, e mais especificamente entre os grupos, pode ter ocorrido em função de que o material utilizado da cultivar Georgiagem, quando retirado do laboratório, apresentava menor qualidade sob o aspecto visual que as demais cultivares, ou seja, apresentava folhas com menor tamanho e menor massa fresca, o que pode ter interferido na resposta das variáveis analisadas. É possível que tal resposta não esteja relacionada às diferenças entre grupos, mas pode ser uma característica intrínseca da própria cultivar.

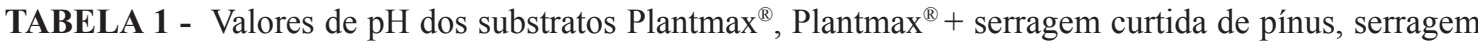
curtida de pínus, Plantmax ${ }^{\circledR}+$ vermiculita expandida de granulometira média e vermiculita expandida de granulometira média. UFPEL/FAEM, Pelotas, 2009.

\begin{tabular}{ll}
\hline \multicolumn{1}{c}{ Substrato } & $\mathrm{pH}$ \\
\hline Plantmax $^{\circledR}$ & 6,1 \\
Plantmax $^{\circledR}+$ serragem curtida de pínus & 5,3 \\
Serragem curtida de pínus $^{\text {Plantmax }}{ }^{\circledR}+$ vermiculita expandida de granulometira média & 5,1 \\
Vermiculita expandida de granulometira média $^{2,8}$ & 7,6 \\
\hline
\end{tabular}

TABELA 2 - Média do número de horas de insolação (h) e radiação solar (cal $\mathrm{cm}^{-2}$ dia $\left.^{-1}\right)$ média, máxima e mínima observada no Câmpus Capão do Leão durante os meses de fevereiro, março e abril de 2009. UFPEL/FAEM, Pelotas, 2009.

\begin{tabular}{ccccc}
\hline & Insolação(h) & \multicolumn{3}{c}{ Radiação solar $\left(\mathrm{cal} \mathrm{cm}^{-2}\right.$ dia $\left.^{-1}\right)$} \\
\cline { 2 - 5 } Mês & Média & Média & Máxima & Mínima \\
Fevereiro & 252,0 & 421,9 & 561,0 & 85,0 \\
Março & 203,7 & 264,5 & 476,0 & 9,0 \\
Abril & 250,3 & 349,1 & 431,0 & 174,0 \\
\hline
\end{tabular}


TABELA 3 - Médias do comprimento das raízes (Cr), comprimento da maior raiz (Mr) e número de raízes (Nr) de diferentes cultivares de mirtileiro. UFPEL/FAEM - Pelotas, 2009.

\begin{tabular}{cccccccccc}
\hline \multicolumn{4}{c}{$\mathrm{Cr}(\mathrm{cm})$} & \multicolumn{3}{c}{$\mathrm{Mr}(\mathrm{cm})$} & $\mathrm{Nr}(\mathrm{cm})$ \\
\hline $\mathrm{S}$ & \multicolumn{1}{c}{ Woodard Bluebelle Georgiagem } & Woodard Bluebelle & Georgiagem & Woodard & Bluebelle & Georgiagem \\
1 & $1,97 \mathrm{Ba}^{*}$ & $1,85 \mathrm{Bba}$ & $1,38 \mathrm{Bb}$ & $2,20 \mathrm{Ba}$ & $2,03 \mathrm{Ca}$ & $1,38 \mathrm{Bb}$ & $1,71 \mathrm{Ca}$ & $1,87 \mathrm{Ca}$ & $1,67 \mathrm{Aa}$ \\
2 & $1,44 \mathrm{Bab}$ & $1,31 \mathrm{Bb}$ & $2,01 \mathrm{Ba}$ & $1,66 \mathrm{Ba}$ & $1,51 \mathrm{Ca}$ & $2,01 \mathrm{Ba}$ & $2,00 \mathrm{Ca}$ & $2,18 \mathrm{BCa}$ & $1,70 \mathrm{Aa}$ \\
3 & $1,40 \mathrm{Ba}$ & $1,72 \mathrm{Ba}$ & $1,85 \mathrm{Ba}$ & $1,92 \mathrm{Ba}$ & $2,17 \mathrm{Ca}$ & $1,85 \mathrm{Ba}$ & $3,87 \mathrm{Aa}$ & $2,62 \mathrm{ABb}$ & $1,72 \mathrm{Ac}$ \\
4 & $1,39 \mathrm{Bc}$ & $2,72 \mathrm{Aa}$ & $1,94 \mathrm{Bb}$ & $1,70 \mathrm{Bc}$ & $3,10 \mathrm{Ba}$ & $1,94 \mathrm{Bb}$ & $2,65 \mathrm{Ba}$ & $2,31 \mathrm{ABCa}$ & $1,70 \mathrm{Ab}$ \\
5 & $3,14 \mathrm{Aa}$ & $3,21 \mathrm{Aa}$ & $3,00 \mathrm{Aa}$ & $4,10 \mathrm{Aa}$ & $4,21 \mathrm{Aa}$ & $3,00 \mathrm{Aa}$ & $2,68 \mathrm{Bab}$ & $2,97 \mathrm{Aa}$ & $2,21 \mathrm{Ab}$ \\
\hline
\end{tabular}

* Letras minúsculas na linha e maiúsculas na coluna não diferem estatisticamente entre si, pelo teste de Tukey, a $1 \%$ de probabilidade de erro. S = Substratos: 1- Plantmax ${ }^{\circledR}$; 2- Plantmax ${ }^{\circledR}+$ serragem curtida de pínus; 3- serragem curtida de pínus; 4- Plantmax ${ }^{\circledR}+$ vermiculita expandida de granulometria média; 5- vermiculita expandida de granulometria média.

TABELA 4 - Médias de altura dos explantes (He), massa fresca total (Mft) e número de brotações (Nb) de diferentes cultivares de mirtileiro. UFPEL/FAEM - Pelotas, 2009.

\begin{tabular}{cccccccccc}
\hline \multicolumn{3}{c}{ He $(\mathrm{cm})$} & \multicolumn{3}{c}{ Mft $(\mathrm{mg})$} & \multicolumn{4}{c}{$\mathrm{Nb}$} \\
\hline $\mathrm{S}$ & Woodard & Bluebelle Georgiagem Woodard & Bluebelle & Georgiagem & Woodard & Bluebelle Georgiagem \\
1 & $3,78 \mathrm{CDa}^{*}$ & $4,37 \mathrm{Aa}$ & $4,29 \mathrm{Aa}$ & $8,03 \mathrm{Cb}$ & $5,87 \mathrm{Cb}$ & $20,73 \mathrm{Aa}$ & $1,31 \mathrm{Aab}$ & $1,47 \mathrm{BCa}$ & $1,10 \mathrm{Bb}$ \\
2 & $5,56 \mathrm{Ba}$ & $4,25 \mathrm{Ab}$ & $4,15 \mathrm{Ab}$ & $6,47 \mathrm{Cb}$ & $28,50 \mathrm{Ba}$ & $23,25 \mathrm{Aa}$ & $1,06 \mathrm{Ac}$ & $2,00 \mathrm{Aa}$ & $1,50 \mathrm{Bb}$ \\
3 & $6,56 \mathrm{Aa}$ & $4,65 \mathrm{Ab}$ & $4,58 \mathrm{Ab}$ & $34,08 \mathrm{Ba}$ & $28,31 \mathrm{Ba}$ & $26,32 \mathrm{Aa}$ & $1,22 \mathrm{Ab}$ & $2,00 \mathrm{Aa}$ & $2,00 \mathrm{Aa}$ \\
4 & $4,49 \mathrm{Ca}$ & $4,49 \mathrm{Aa}$ & $4,30 \mathrm{Aa}$ & $48,12 \mathrm{Aa}$ & $38,14 \mathrm{ABb}$ & $23,97 \mathrm{Ac}$ & $1,28 \mathrm{Aab}$ & $1,50 \mathrm{Ba}$ & $1,12 \mathrm{Bb}$ \\
5 & $3,65 \mathrm{Db}$ & $4,63 \mathrm{Aa}$ & $4,33 \mathrm{Aab}$ & $53,88 \mathrm{Aa}$ & $42,35 \mathrm{Ab}$ & $25,70 \mathrm{Ac}$ & $1,12 \mathrm{Aa}$ & $1,10 \mathrm{Ca}$ & $1,18 \mathrm{Ba}$ \\
\hline
\end{tabular}

* Letras minúsculas na linha e maiúsculas na coluna não diferem estatisticamente entre si, pelo teste de Tukey, ao nível de $1 \%$ de probabilidade de erro. $\mathrm{S}=$ Substratos: 1- Plantmax $^{\circledR} ; 2$ - Plantmax $^{\circledR}+$ serragem curtida de pínus; 3- serragem curtida de pínus; 4- Plantmax $^{\circledR}$ + vermiculita expandida de granulometria média; 5-vermiculita expandida de granulometria média.
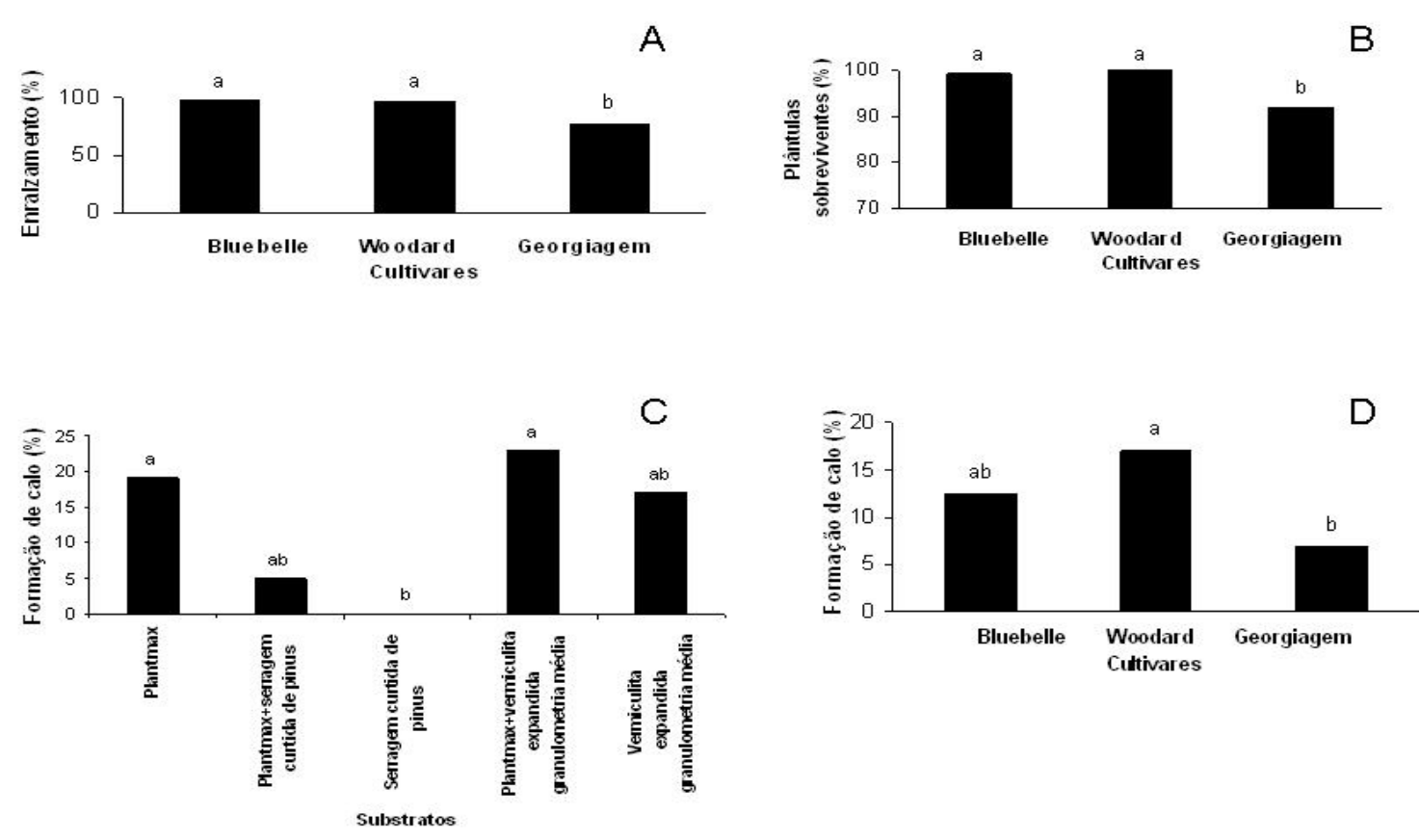

FIGURA 1 - Percentagem de enraizamento (A), percentagem de plântulas sobreviventes (B), percentagem de formação de calo em função dos substratos (C) e em função das diferentes cultivares (D) de mirtileiro. Letras minúsculas iguais entre si não diferem estatisticamente, pelo teste de Tukey, a 5\% de probabilidade de erro. UFPEL/FAEM - Pelotas, 2009. 


\section{CONCLUSÕES}

1-Recomenda-se o uso dos substratos vermiculita expandida de granulometria média, serragem curtida de pínus e Plantmax ${ }^{\circledR}+$ vermiculita expandida de granulometria média para o enraizamento ex vitro de plântulas de mirtileiro.

2-Maior enraizamento ex vitro é alcançado com as cultivares Bluebelle e Woodard (Grupo Rabbiteye).

\section{AGRADECIMENTOS}

Os autores agradecem ao Ministério da Ciência e Tecnologia (MCT), ao Conselho Nacional de Desenvolvimento Científico e Tecnológico (CNPq), à Fundação de Amparo à Pesquisa do Estado do Rio Grande do Sul (FAPERGS) e à Coordenação de Aperfeiçoamento de Pessoal de Nível Superior (CAPES), pelo apoio financeiro.

\section{REFERÊNCIAS}

ANTUNES, L. E. C. Potencial de produção de pequenas frutas em diferentes regiões do Sul do Brasil. In: Encontro Nacional de Fruticultura de Clima Temperado, 8., 2005, Fraiburgo. Anais... Caçador: Epagri, 2005. p.61-62.

BATAGLIA, O.C.; ABREU, C.A. Análise química de substratos para crescimento de plantas: um novo desafio para cientistas de solo. Viçosa: SBCS, 2001. p. 8-9 (Boletim Informativo, 26).

CASTILLO, A.; SORIA, J.; CARRAU, F.; LEONI, C. E.; PEREIRA, G. Investigación en arandanos en Uruguay: propagación in vitro y evaluación de variedades por INIA. In: SIMPÓSIO NACIONAL DO MORANGO, 2.; ENCONTRO DE PEQUENAS FRUTAS E FRUTAS NATIVAS, 2004, Pelotas. Palestras e Resumos... Pelotas: Embrapa Clima Temperado, 2004. p.225-228. (Documentos, 124).

DAMIANI, C. R.; SCHUCH, M. W. Enraizamento in vitro de mirtilo em condições fotoautotróficas. Ciência Rural, Santa Maria, v. 39, n. 4, p. 10121017, 2009a.

DAMIANI, C. R.; SCHUCH, M. W. Diferentes substratos e ambientes no enraizamento in vitro de mirtilo. Ciência Rural, Santa Maria, v. 39, n. 2, p. 563-566, 2009b.
FACHINELLO, J. C.; HOFFMANN, A.; NACHTIGAL, J. C.; KERSTEN, E. Propagação vegetativa por estaquia. In: FACHINELLO, J. C.; HOFFMANN, A.; NACHTIGAL, J. C. Propagação de plantas frutíferas. Brasília: Embrapa Informação Tecnológica, 2005. p. 69-109.

FERRAZ, M. V.; CENTURION, J. F.; BEUTLER, A. N. Caracterização física e química de alguns substratos comerciais. Acta Scientiarum Agronomy, Maringá, v. 27, n. 2, p. 209-214, 2005.

FERRI, V.C.; CENTELLAS, A. Q.; HELBIG, V.E.; FORTES, G.R.L. Uso de ágar, amido e ácido indolbutírico no enraizamento in vitro do porta-enxerto de macieira MM 111. Ciência Rural, Santa Maria, v. 28, n. 4, p. 561-565, 1998.

HOFFMANN, A.; NACHTIGAL, J. C.; FACHINELLO, J. C. Infraestrutura para propagação de plantas frutíferas. In: FACHINELLO, J. C.; HOFFMANN, A.; NACHTIGAL, J. C. Propagação de plantas frutíferas. Brasília: Embrapa Informação Tecnológica, 2005. p. 13-43.

KÄMPF, A. N. Análise física de substratos para plantas. Viçosa: SBCS, 2001. p. 5-7. (Boletim Informativo, 26)

KÄMPF, A. N. Substrato. In: KÄMPF, A.N. Produção comercial de plantas ornamentais. Guaiba: Agropecuária, 2005. p. 45-72.

LLOYD, G.; McCOWN, B. Commercially-feasible micropropagation of mountain laurel, Kalmia latifolia, by use of shoot-tip culture. Proceedings International Plant Propagators Society, Ashville, v.30, p.421-427, 1980.

MACHADO, A. A.; CONCEIÇÃO, A. R. Sistema de análise estatística para Windows: Winstat. Versão 2.0. Pelotas: UFPel, 2003.

MACIEL, S. da C.; VOLTOLINI, J. A.; PEDROTTI, E. L. Enraizamento ex vitro e aclimatação do portaenxerto de macieira Marubakaido micropropagado. Revista Brasileira de Fruticultura, Jaboticabal, v. 24, n. 2, p. 289-292, 2002.

McCLELLAND, M.T.; SMITH, M.A.L.; CAROTHERS, Z.B. The effects of in vitro and ex vitro root initiation on subsequent microcutting root quality in three woody plants. Plant Cell Tissue and Organ Culture, Dordrecht, v. 23, p. 115-123, 1990. 
MIRANDA, E. M. de; MIRANDA, K. R. de. Propagação vegetativa de mogno (Swietenia macrophylla King) por enraizamento de estacas semilenhosas em câmara úmida. Rio Branco: EMBRAPA Acre, 2000. 15 p. (Circular Técnica, 32).

PAGOT, E. Cultivo de pequenas frutas: amorapreta, framboesa, mirtilo. Porto Alegre: EMATER/ RS-ASCAR, 2006.

PEDROTTI, E. L.; VOLTOLINI, J. A. Enraizamento ex vitro e aclimatização do porta-enxerto de macieira M.9. Revista Brasileira de Fruticultura, Jaboticabal, v.23, n.2, p.234-239, 2001.
TREVISAN, R.; FRANZON, R. C.; FRITSCHE NETO, R.; GONÇALVES, R. da S.; GONÇALVES, E. D.; ANTUNES, L. E. C. Enraizamento de estacas herbáceas de mirtilo: influência da lesão na base e do ácido indolbutírico. Ciência e Agrotecnologia, Lavras, v.2, n. 2, p. 402-406, 2008.

XAVIER, A.; WENDLING, I.; SILVA, R. L da. Silvicultura clonal: princípios e técnicas. Viçosa: Editora UFV, 2009. 272 p. 